\title{
Predicting outcome in patients with intracranial aneurysms with the help of microsurgery
}

\author{
L ARTIOLA I FORTUNY AND C B T ADAMS \\ From the Department of Neurological Surgery, The Radcliffe Infirmary, Oxford
}

SUMMARY A follow-up study of 265 patients treated by microsurgical techniques for ruptured intracranial aneurysms at the Department of Neurological Surgery of the Radcliffe Infirmary, Oxford from 1972 to 1977 showed that prediction of results in terms of mortality, and various measures of morbidity could be achieved by considering before operation several variables in combination. Age, systemic blood pressure on admission and before operation were the most important factors in determining outcome. Inclusion of a variable following operation-arterial spasm-was found to improve prediction somewhat. In addition, spasm was found to be the single most important factor in predicting both mortality and morbidity.

Patients who undergo microneurosurgery for ruptured or unruptured intracranial aneurysms may recover completely, may be left with various degrees of permanent disability or may die. So many factors may affect the outcome that it is difficult to predict in the early period after operating what the likely course will be, taking each factor in isolation. ${ }^{1}$ An additional problem is the actual measurement of outcome. There have been relatively few studies which measure results in more than the gross terms of physical survival and capacity to return to work. ${ }^{2}$ Outcome can be relative to previous status and earnings, subjective well-being, and resumption of social activities. These indices are not synonymous and each may have important information to contribute towards an understanding of the quality of life that the patient achieves. The present study was undertaken in order (a) to measure in detail the personal, physical, social and occupational factors that are relevant to the evaluation of functional recovery in an aneurysm population and (b) to define what combination of clinical and social factors best predicts the various aspects of outcome.

\section{Patients and methods}

The records of all patients who were treated with the help of microsurgery intracranial aneurysms at the Department of Neurological Surgery, The Radcliffe Infirmary, Oxford, between January 1972 and July 1977 were carefully examined. There were 265 patients of whom $61(23 \%)$ died at various times between the operation and the beginning

Address for reprint requests: Mr CBT Adams, Department of Neurological Surgery, The Radcliffe Infirmary, Oxford OX2 6HE.

Accepted 23 December 1980 of the study. In $86.9 \%$ of those who died, death was directly attributable to the aneurysm. The 204 survivors were contacted by post. They were asked to complete a questionnaire especially designed to elicit as much information as possible regarding the patient's assessment of his present physical condition and feeling of well-being, as well as details of his working life and leisure interests. In addition the patients also completed the General Health Questionnaire ${ }^{3}$ included as a measure of psychiatric morbidity that has yielded useful information in comparable studies of other patients populations ${ }^{4}$; the response rate was $94 \cdot 1 \%$. Thus, only 12 patients were lost to follow-up. Care was taken to ascertain that these patients had not in fact died by checking with both general practitioners and the regional Family Practioners Committee.

\section{FACTORS WHICH MAY INFLUENCE OUTCOME}

These can be divided into two groups: (1) biological (clinical) factors and (2) social and economic factors. Information regarding the subdivision of each factor is documented in table 1. As far as early results after operation are concerned, it may be intuitively unlikely, for example, that the socio-economic status of an individual has a great role to play. However, surveys published by the $\mathrm{OPCS}^{5}$ indicate clear differences between the social classes vis-à-vis mortality secondary to subarachnoid haemorrhage. It is therefore well worth considering such social factors as occupational class, marital status and gainful employment not only in the evaluation of long-term results but also in the early period after operation. The selection of clinical factors which may influence outcome has been discussed elsewhere. ${ }^{7}$ These are listed in table 1 . Information regarding outcome was classified in the following manner: (1) residual neurological problems: this aspect of outcome involved the presence or absence of physical disability (motor and sensory deficits as well as aphasic problems) one to five years after operation; (2) physical independence: 
Table 1 Variables included in the analysis groups

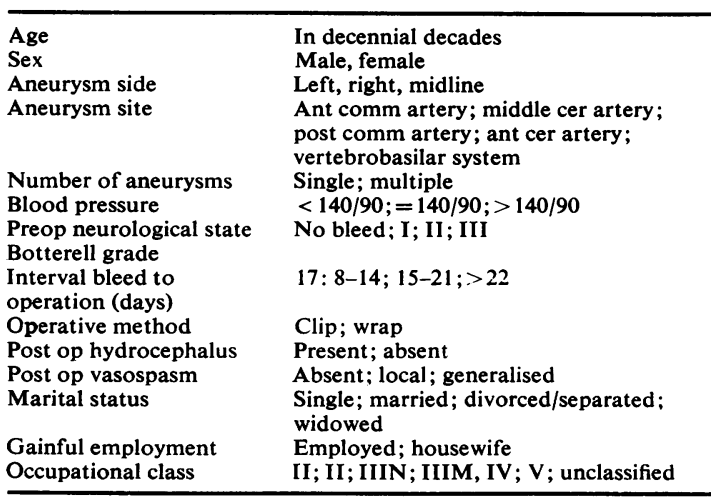

this involved the amount of help the patient needed from a second person in order to get by in daily activities. Patients were totally dependent on someone else, partially dependent (that is taking baths, climbing stairs) or totally independent (although they may show residual neurological problems); (3) return to work: a scoring system was developed in order to assess to what extent the patient had returned to his or her premorbid working situation. This applied to housewives as well. Thus, information regarding full-time return to work included such important details as salary decrease or job demotion secondary to the illness under investigation. Unemployment for other causes was also taken into account; (4) social activities and hobbies: changes in premorbid social life and other leisure activities (such as sports, home improvements, arts and crafts, etc) were recorded; (5) subjective well-being: this is obviously a less tangible measure of outcome. However, clinical experience with aneurysm patients suggests that it may be an important one. Patients were asked to evaluate how they felt about energy, self-confidence, patience, eating and sleeping, relative to before their illness. The combined score obtained was recorded; (6) psychiatric morbidity (General Health Questionnaire). The standard scoring method was used: a score of over 11 was considered to be within the morbid range.

STATISTICAL TREATMENT OF THE DATA

Comparisons between the effect of individual variables upon mortality ${ }^{1}$ and morbidity ${ }^{6}$ have been documented elsewhere. It was known from our own studies and from previous reports that there was a high correlation between some clinical factors and outcome. In order to specify which combination of factors gave the best prediction for each measure of outcome, discriminant function analyses were carried out. A stepwise method which takes into consideration the differences between all the centroids and the homogeneity within the groups was used. In the first group of analyses only factors before operation (including clinical and social data) were considered for the prediction of outcome. In the second group operative (clip or wrap) and later (spasm and hydrocephalus) variables were also included. These analyses were carried out because the operative method (clipping or wrapping of the aneurysm) and the presence of vasospasm and hydrocephalus after operation were shown to be very important in the prediction of mortality. ${ }^{1}$ Information concerning the presence or absence of vasospasm after operation was available on only $64.1 \%$ of the population. Therefore the second group of analyses were performed on a smaller population sample $(n=170)$.

\section{Results}

Table 2 shows the distribution of patients in each individual outcome measured. The figures clearly indicated that morbidity after operation was high, especially with regard to working efficiency and subjective well-being. Only slightly more than half of the population remained totally unaffected as far as job situation was concerned. Only about $40 \%$ of the patients reported to be feeling as well as before their illness. The other outcome measures yielded a return to premorbid levels in more than $60 \%$ of the population.

Prediction results The first set of discriminant function analyses yielded the following results: Of the clinical variables only the following contributed significantly to the various aspects of outcome: age, sex, side of aneurysm, number of aneurysms, systemic

Table 2 Distribution of patients in each outcome

\begin{tabular}{|c|c|c|}
\hline Residual neurological problems & $n$ & Proportion \\
\hline $\begin{array}{l}\text { Present } \\
\text { Absent }\end{array}$ & $\begin{array}{r}77 \\
127\end{array}$ & $\begin{array}{l}37 \cdot 7 \% \\
62 \cdot 3 \%\end{array}$ \\
\hline $\begin{array}{l}\text { Physical independence } \\
\text { Totally dependent } \\
\text { Part dependent } \\
\text { Independent }\end{array}$ & $\begin{array}{r}16 \\
17 \\
171\end{array}$ & $\begin{aligned} 7.8 \% & \\
8.3 \% & \text { (21.5\% residual } \\
83.8 \% & \text { problems present; } \\
& 78.5 \% \text { residual } \\
& \text { problems absent })\end{aligned}$ \\
\hline $\begin{array}{l}\text { Working efficiency } \\
\text { No return } \\
\text { Part-time return } \\
\text { Full-time return with job }\end{array}$ & $\begin{array}{l}43 \\
16\end{array}$ & $\begin{array}{r}21 \cdot 1 \% \\
7 \cdot 8 \%\end{array}$ \\
\hline $\begin{array}{l}\text { demotion and salary decrease } \\
\text { Full-time return with either }\end{array}$ & 8 & $3.9 \%$ \\
\hline & 27 & $13 \cdot 2 \%$ \\
\hline $\begin{array}{l}\text { job or equivalent } \\
\text { No information }\end{array}$ & $\begin{array}{r}104 \\
6\end{array}$ & $\begin{array}{r}51.0 \% \\
2.9 \%\end{array}$ \\
\hline $\begin{array}{l}\text { Social activities/hobbies } \\
\text { Detrimental change } \\
\text { No change } \\
\text { No information }\end{array}$ & $\begin{array}{r}60 \\
132 \\
12\end{array}$ & $\begin{array}{r}29 \cdot 4 \% \\
64 \cdot 7 \% \\
5.9 \%\end{array}$ \\
\hline $\begin{array}{l}\text { Psychiatric morbidity } \\
\text { (General Health Questionnaire) } \\
\text { Unable to complete }\end{array}$ & & \\
\hline $\begin{array}{l}\text { questionnaire } \\
\text { Abnormal profile } \\
\text { Normal profile } \\
\text { No information }\end{array}$ & $\begin{array}{r}5 \\
55 \\
132 \\
12\end{array}$ & $\begin{array}{r}2.4 \% \\
27.0 \% \\
64.7 \% \\
5.9 \%\end{array}$ \\
\hline $\begin{array}{l}\text { Subjective well-being } \\
\text { Much worse than before } \\
\text { illness } \\
\text { Worse than before illness } \\
\text { As good as before illness } \\
\text { No information }\end{array}$ & $\begin{array}{l}42 \\
67 \\
83 \\
12\end{array}$ & $\begin{array}{r}20.6 \% \\
32.8 \% \\
40.7 \% \\
5.9 \%\end{array}$ \\
\hline
\end{tabular}


blood pressure, neurological state before operation and interval between bleed and operation. Of these variables, age and neurological status before operation were involved in all measures of outcome: the lower the age and the better the neurological status, the better the prognosis. Systemic blood pressure was involved in outcome with regard to survival, residual problems, independence and social activities: patients with hypertension and borderline hypertension on admission show a worse prognosis than normotensives. Side of aneurysm was important in all aspects of outcome except return to work and social activities. The best prognosis as far as morbidity is concerned was found for patients with midline aneurysms (anterior communicating artery, posterior fossa) followed by patients with right sided aneurysms. Conversely, patients with left-sided aneurysms survived more often than patients with either right sided or midline aneurysms. The sex of the patient was important in the prediction of survival, return to work and especially psychiatric morbidity. Indeed, men showed a much better prognosis than women. In survival, independence and return to work, timing of the operation was an important variable. Prognosis appears to be somewhat better in patients operated on 15 days after the bleed. Patients with anterior communicating artery aneurysms had the lowest incidence of residual neurological problems followed by patients with aneurysms of the posterior communicating and internal carotid arteries. Patients with multiple aneurysms seemed to have a better prognosis with regard to subjective well-being and psychiatric morbidity-although the reason for this is unclear.

As far as the social variables are concerned, marital status, gainful employment and occupational class do seem to play some role in prognosis: the highest mortality was found in class IV, patients in occupational classes I and II had the worst prognosis for residual physical problems. Patients in classes I and V have a worse prognosis than people in other classes for a return to work and the same applies for return to previous social activities. There is a clear gradient of worsening prognosis with lowering of the socioeconomic class in psychiatric morbidity and subjective well-being. Widowed patients had a worse prognosis for independence than other patients. Single people had the worst prognosis with regard to social activities, whereas separated and divorced patients had a higher probability of abnormal psychiatric profiles than patients in other marital states. Being gainfully employed was a positive factor in psychiatric outcome, whereas housewives were likely to return to their housework more often than people who were gainfully employed were to return to work.

Table 3 shows the contribution of each factor to each aspect of outcome as well as the percentage of cases correctly predicted and the significance of the function derived.

In the second group of discriminant function analyses, operative method (clip or wrap), vasospasm and hydrocephalus after operation were added to the previous factors. Interestingly, age remained the most common predictor for all aspects of outcome. However, vasospasm after operation became the single most important predicting factor in mortality and three measures of morbidity (residual problems, independence and return to work) and was also important in social activities and psychiatric morbidity. Patients who developed this condition did significantly less well than other patients. Table 4 shows the relative contribution of each factor to outcome, the prediction results and the significance level of the discriminant functions when spasm, hydrocephalus and operative method are added to the variables present before operation. In this set of results a number of factors before operation which contributed to the prediction of outcome in the previous analyses are "pushed over" by the overriding effect of vasospasm. This does not mean that such variables as age, neurological state before operation and systemic blood pressure on admission do not contribute to the patient's ultimate fate. It means, however, that spasm is a more powerful factor in the prediction of outcome than the other variables when all variables are combined. In using only a sample of the population for these analyses using variables before and after operation, some small differences may have been introduced between these results and those of the previous analyses (using pre-operation variables only). However, there were no important statistical differences between this sample and the rest of the population with regards to each individual variable. ${ }^{1}$

\section{Discussion}

The results show that, by and large, the combination of increasing age, worsening neurological status and development of vasospasm after operation leads to the high probability of a poor outcome, regardless of the measure used. Hypertension on admission together with these other deleterious factors contributes to poor outcome in the more tangible measures (residual problems, independence, return to work and social activities). Patients with left-sided aneurysms in combination with other factors did worse than patients with aneurysms in other locations with regard to residual problems and social activities. It is thought that the aphasic disorders which are present in these patients may account for their complaint of residual problems and their decreased ability to 
618

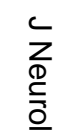

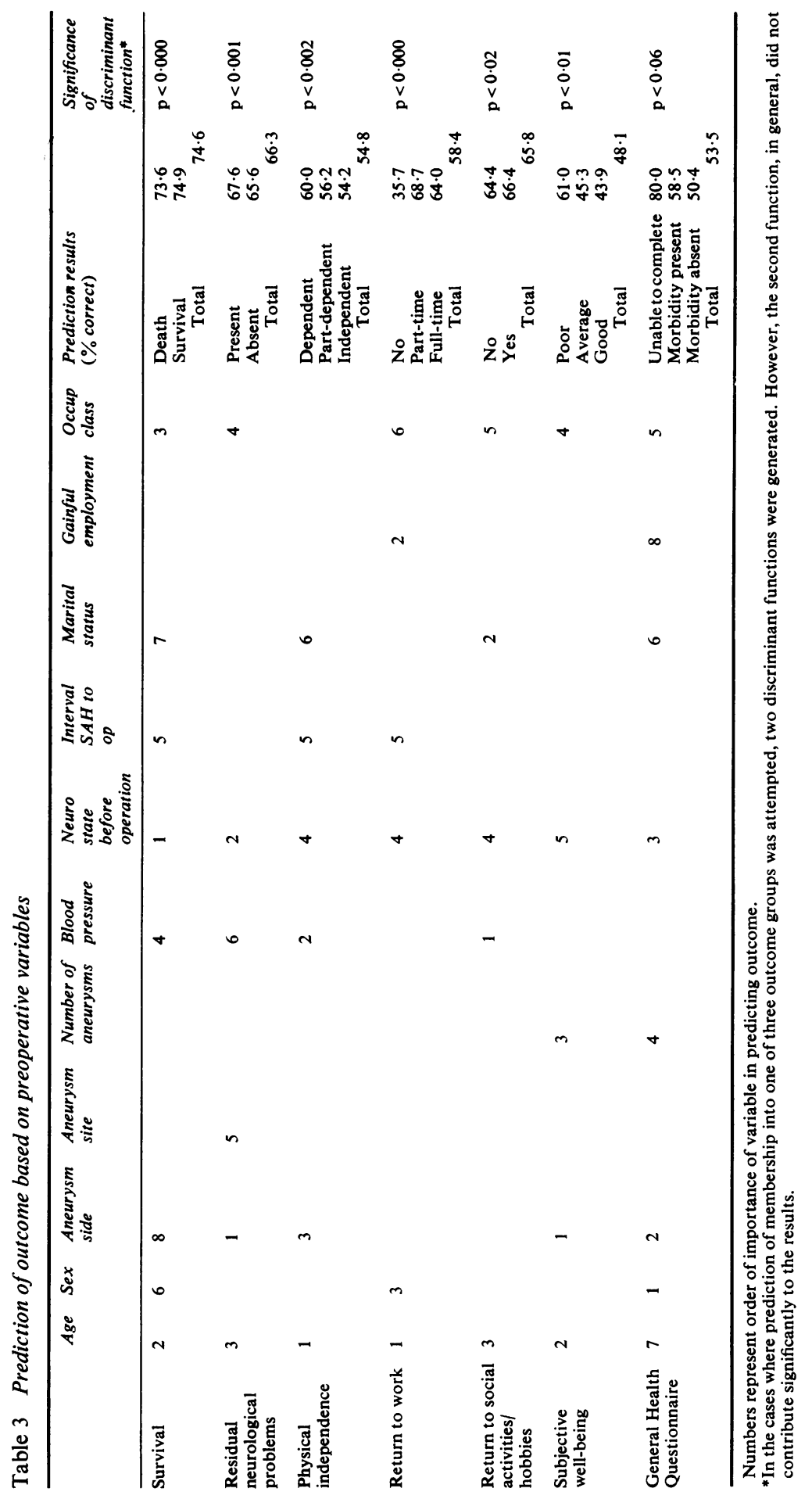

D

蛋

흠

क

$\overrightarrow{0}$
$\overrightarrow{\vec{\omega}}$
$\stackrel{\circ}{\vec{J}}$
$\overrightarrow{0}$

A

जे

윽

묻

응드

흠.

밍

产

융

혹

륨

흥

을.

옳

옥

을.

N

స్

श्र

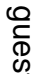




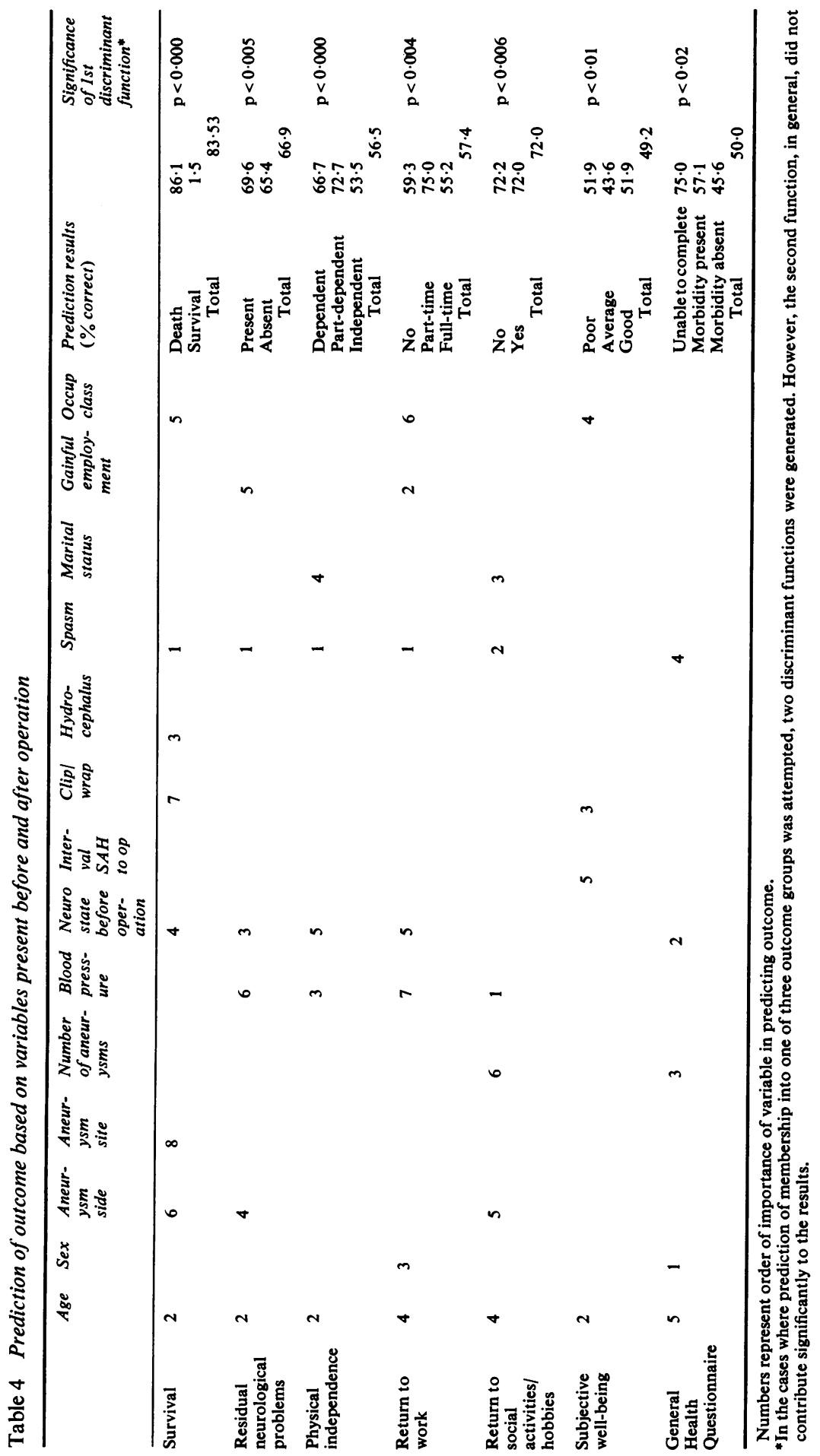


behave socially. Female patients had a poorer prognosis in terms of return to work and psychiatric morbidity. It is clear that a number of women may not have returned to work because the economic pressure on them may be less than that on their male counterparts. The higher psychiatric morbidity in women in the general population ${ }^{3} 7$ is well documented and has been commented on elsewhere. ${ }^{6}$ The effects of marital status on the various outcome measures are of interest. Widowed patients tended to be older and it is not surprising they needed the help of a second person more often. It is unclear why single people should report more negative changes in their social activities than other patients. However, the relationship between broken marriages and a poor psychiatric profile is well known. ${ }^{38}$ Similarly, it is not surprising that housewives had a higher probability of returning to their household duties than patients who were gainfully employed were to return to work. Indeed, it can be argued that doing housework is less demanding than holding a 9 to 5 job and doing the housework!

It is important to note that a number of the factors considered have been shown to affect outcome independent of the other factors. ${ }^{19}$ By contrast, some factors become important in prognosis only in combination with other variables. The independent effect of the factors considered here on the various measures of outcome has been discussed elsewhere. ${ }^{6}$ The combining of a number of factors for the prediction of outcome is undoubtedly valuable especially as regards mortality. Prediction is not nearly as accurate when finer aspects of outcome are considered and when there are more than two outcome possibilities within one outcome measure. The predictive power of the parameters considered here is nevertheless important even though the amount of data used is relatively small. The inclusion of social variables in the analysis is, for the most part, academic as they do not raise the predictive power of the clinical variables considerably. Prediction, however, could conceivably be raised by the addition of laboratory data such as biochemical and electroencephalic values and computerised tomography information.

It is evident that the various outcome measures yield different results. It would be unreasonable to expect that the neurosurgeon in the busy out-patient clinic increase his work load in an attempt to obtain detailed documentation on all the aspects of the patient's life. In our society, the most importantand most commonly used-measure of outcome may be return to work. However, it is necessary to point out that especially where women are concerned, an effort should be made to find out whether the patient is back to her premorbid job. It is not enough to say that a woman has returned to her housework, as a great number of women, especially in the lower socioeconomic classes, are gainfully employed. Their loss of employment usually represents a heavy burden to their families. In addition, neglecting to consider this factor may lead to unreasonably inflated figures with regard to outcome.

It is thought that the prediction of outcome in individual patients is of considerable interest to the clinician who is making decisions at the bedside. If he were to know with a reasonable degree of accuracy what outcome was probable he may be able to judge whether operating is justifiable, or whether it is worth attempting to wait until some of the factors improve (such as blood pressure and neurological status). It is evident that one factor, vasospasm after operation, is very important. Unfortunately there does not exist, as yet, a way to treat this condition except, perhaps by reducing the likelihood of its occurrence by delaying operation.

Thanks are due to $\mathrm{Mr} \mathrm{M}$ Briggs and $\mathrm{Mr} \mathrm{R}$ Gye for permission to include their patients in the series and to Mrs J Smith for invaluable secretarial assistance. The study was supported by Medical Research Council Project Grant No G 977/184/N.

\section{References}

1 Artiola i Fortuny, L, Prieto-Valiente L. Long-term prognosis in surgically treated intracranial aneurysms -I Mortality. J Neurosurg 1981; 54: 26-35.

2 Oddy M, Humphrey M, Uttley D. Subjective impairment and social recovery after closed head injury. J Neurol, Neurosurg Psychiatry 1978; 41 : 611-6.

3 Goldberg DP. Detection of Psychiatric Illness by Questionnaire-Maudsley Monograph No 1. London: Oxford University Press, 1972.

4 Maguire GP, Julier D, Hawton K, Bancroft J. Psychiatric morbidity and referral in general medical wards. Br Med J, 1974; I:268.

5 Office of Population Censuses and Surveys, Mortality statistics-Cause-England and Wales. London: HMSO, 1976.

6 Artiola i Fortuny L, Prieto-Valiente L. Long-term prognosis in surgically treated intracranial aneurysms -II Morbidity. J Neurosurg 1981 ; 54: 35-44.

7 Silverman C. The Epidemiology of Depression. Baltimore: The Johns Hopkins Press, 1968.

8 Briscoe CW, Smith MD. Depression and marital turmoil. Arch Gen Psychiatry 1973; 29:812-7.

9 Artiola i Fortuny L, Adams CBT, Briggs M. Surgical mortality in an aneurysm population-Effects of age, blood pressure and preoperative neurological state. J Neurol Neurosurg Psychiatry 1980; (in press) 